\title{
Dimethacrylate polymers with different glycerol content
}

\author{
Thermal study, degree of conversion, and morphological features
}

\author{
Rafael Turra Alarcon ${ }^{1} \cdot$ Caroline Gaglieri $^{1} \cdot$ Gilbert Bannach $^{1}$ \\ Received: 19 August 2017 / Accepted: 3 February 2018 / Published online: 20 February 2018 \\ (C) Akadémiai Kiadó, Budapest, Hungary 2018
}

\begin{abstract}
The objectives of this study were to verify thermal properties, degree of conversion, and morphological features of several dimethacrylate polymers with different glycerol content and obtain the better proportion system to decrease cost of final polymer. These polymers were synthesized by photopolymerization, which has economic and ecological advantages. The glycerol can be used as a coinitiator in photopolymerization and has the advantage of being inexpensive and non-toxic; thus, it is in the scope of the green chemistry principles. Simultaneous thermogravimetry-differential thermal analysis and derivative thermogravimetric, differential scanning calorimetry, middle infrared spectroscopy, and scanning electronic microscopy were used to determine thermal properties, degree of conversion, and morphological characteristics of polymers obtained. The thermoanalytical results showed that glycerol addition in the dimethacrylate system caused few modifications in the thermal stability of the polymer and thermal events when compared with pure polymers (without glycerol). Two dimethacrylate systems (UDMA/glycerol and Bis-GMA/glycerol) showed good results for conversion degree and morphological aspects when compared with pure systems.
\end{abstract}

Keywords Photopolymerization · Dimethacrylates · Thermal analysis · Glycerol · Conversion degree

\section{Introduction}

Photocuring techniques of polymerization are interesting due to their ease of synthesis, economic and ecological benefits, fast curing, low energy demand, ability to perform at room temperature, low toxicity, and relatively inexpensive cost, when compared to common thermal methods for polymerization [1-8]. All these advantages are in agreement with the green chemistry principles [9, 10]. This type of polymerization is widely used to obtain new materials, such as biomaterials, coatings, optical materials, and composites [6, 11-16]. Dimethacrylate monomers are easily polymerized by radical systems and have broad

Electronic supplementary material The online version of this article (https://doi.org/10.1007/s10973-018-7055-8) contains supplementary material, which is available to authorized users.

Gilbert Bannach

gilbert@fc.unesp.br

1 Chemistry Department, School of Science, São Paulo State University (UNESP), Bauru, SP 17033-260, Brazil applicability. The following monomers are used: diurethane dimethacrylate (UDMA), triethylene glycol dimethacrylate (TEGDMA), bisphenol a glycerolate (BisGMA), and bisphenol a ethoxylate (Bis-EMA); these are the most used monomers to produce biomaterials and in industry. The two-component (Type II) method is the most widely used in photopolymerization (polymerization by UV or visible light), applying camphorquinone as initiator and coinitiators such as ethyl-p-dimethylaminobenzoate, which can be combined with glycerol [17-20], which is a non-toxic compound and is considered as "generally recognized as safe" (GRAS) [21].

Thermoanalytical techniques such as simultaneous thermogravimetry-differential thermal analysis (TG-DTA) and differential scanning calorimetry (DSC) are used in order to determine their thermal stability, degradation steps, glass transition, melt, and polymer temperature cure in other works [22-24]. To verify the extent to which polymerization occurs when using different ratios of glycerol in the dimethacrylate systems, middle infrared spectroscopy (MIR) could be used [17-20]. Scanning 
electron microscope (SEM) is widely used to analyze the morphological aspects of the polymers [25, 26].

The addition of glycerol in the dimethacrylate systems could be advantageous due to the decrease in polymer cost because less dimethacrylate monomer is used in the process.

\section{Experimental}

\section{Preparation of photoinitiator solution}

The photoinitiator solutions were made by dissolving $0.01 \mathrm{~mol}$ of camphorquinone (CQ) 97\% (Aldrich) in $10 \mathrm{~mL}$ of acetone P. A (Aldrich) with $0.01 \mathrm{~mol}$ of ethyl-pdimethylaminobenzoate $99 \%$ (Aldrich). Then, $0.2 \mathrm{~mL}$ of this solution was added to the monomeric mixtures.

\section{Preparation of the monomeric mixtures}

To prepare the monomeric mixtures, each dimethacrylate monomer (UDMA, TEGDMA, Bis-EMA, and Bis-GMA, Aldrich) was added into four individual plastic containers, each with $0.01 \mathrm{~mol}$ of the monomer, for a total of 16 containers. Then, in four different containers (one of each monomer), $0.01 \mathrm{~mol}$ of glycerol (Merck) was added. This process was repeated by adding 0.03 and $0.05 \mathrm{~mol}$ of glycerol in each monomer. One container per monomer remained without glycerol, as a control. Thus, in end, 16 different mixtures were obtained. The polymers were named as PMonomer name- system number (monomer/ glycerol), for example, the UDMA polymer without glycerol as called PUDMA, and the polymer $(0.01 \mathrm{~mol}$ of monomer) mixture with $0.01 \mathrm{~mol}$ of glycerol as called PUDMA 11, in the same way, the polymer with $0.01 \mathrm{~mol}$ of monomer and 0.03 mol of glycerol was called PUDMA 13. Therefore, all the samples names are: PUDMA, PUDMA 11, PUDMA 13, PUDMA 15, PTEGDMA, PTEGDMA 11, PTEGDMA 13, PTEGDMA 15, PGMA, PGMA 11, PGMA 13, PGMA 15, PEMA, PEMA 11, PEMA 13, and PEMA 15.

\section{Photopolymerization}

The final mixtures containing monomers and initiator system were photopolymerized using the light emission equipment D-2000 (DMC Ltd., São Carlos, SP, Brazil), which uses LED to emit blue light in the 430-490 nm range, as specified by the manufacturer. The mixtures were placed in a Teflon mold, $1.5 \mathrm{~mm}$ in depth and $3.0 \mathrm{~mm}$ in diameter, and were polymerized for $400 \mathrm{~s}$. After that, the cured polymers underwent thermal and microscopic analyses.

\section{Sample characterization}

Thermal analysis: thermogravimetry (TG),
differential thermal analysis (DTA),
and differential scanning calorimetry (DSC)

Simultaneous TG-DTA curves for each polymer were obtained using the thermal analysis system from Netzsch, model STA 449 F3. Approximately, $15 \mathrm{mg}$ of sample was measured and placed in a $70-\mathrm{mL} \alpha$-alumina open crucible. The parameters were set at a heating rate of $10.0{ }^{\circ} \mathrm{C} \mathrm{min}^{-1}$ and a flow rate of $50.0 \mathrm{~mL} \mathrm{~min}^{-1}$ in a dry air atmosphere. The temperature range was from 30.0 to $800.0^{\circ} \mathrm{C}$.

The DSC analyses were obtained on Mettler-Toledo equipment, model DSC $1 \mathrm{Star}^{\mathrm{e}}$ System, using $40-\mu \mathrm{L}$ closed aluminum crucibles with perforated lids, samples of about $10 \mathrm{mg}$ without previous thermal treatment, a heating rate of $10.0{ }^{\circ} \mathrm{C} \min ^{-1}$ in dry air atmosphere, and a $50.0 \mathrm{~mL} \mathrm{~min}^{-1}$ flow rate. The first cooling step was performed from 25.0 to $-35.0{ }^{\circ} \mathrm{C}$, with isotherm at $-35.0^{\circ} \mathrm{C}$ for $10 \mathrm{~min}$. Then, the first heating step was performed from -35.0 to $130.0^{\circ} \mathrm{C}$. The second cooling step was carried out from 130.0 to $-35.0{ }^{\circ} \mathrm{C}$ (isotherm at $-35.0{ }^{\circ} \mathrm{C}$ for $10 \mathrm{~min}$ ). The second heating step was equal to first one $\left(-35.0-130.0{ }^{\circ} \mathrm{C}\right)$. Finally, the third cooling step was performed from 130.0 to $25.0{ }^{\circ} \mathrm{C}$.

\section{Middle infrared spectroscopy (MIR)}

To calculate the degree of conversion for each polymer, a spectrophotometer from Bruker, model Vertex 70, was used. The equipment was operated in the range of 4000 $400 \mathrm{~cm}^{-1}$. Monomeric mixtures were placed over the diamond crystal and polymerized, while the transmittance (T\%) of each sample was collected. Data were collected every $10 \mathrm{~s}$, and 40 measurements were made for all samples. Equation (1) was used to quantify the degree of conversion for each sample [19, 20, 27, 28].

$\mathrm{DC}(\%)=\left[1-\frac{T_{\mathrm{t}=\mathrm{x}}(\mathrm{C}=\mathrm{C})}{T_{\mathrm{t}=0}(\mathrm{C}=\mathrm{C})}\right] \times(-1000)$

This formula was used to calculate the percent of degree of conversion (DC) using the transmittance of double carbon bonds $(\mathrm{C}=\mathrm{C})$ present in the monomer. Transmittance of the $\mathrm{C}=\mathrm{C}$ bond can be observed near the wavenumber $1640 \mathrm{~cm}^{-1}$. At the initial time $(t=0)$, a minimum transmittance is observed at this wave number, as polymerization has not yet begun. At any other future time $(t=x)$, the transmittance increases, as polymerization occurs and double bonds are cleaved. With this input of data and applying Eq. (1), the degree of conversion over time was plotted in graphs. 


\section{Scanning electronic microscopy (SEM)}

To study of the morphology of the polymer, an EVO LS15 scanning electronic microscope from Zeiss was used. Preparation of the samples involved powdering them, placing them over a carbon adhesive, and finally plating them with gold. The voltage was set at $15 \mathrm{kV}$, and the samples were magnified 1000 times in a high vacuum environment $\left(10^{-3} \mathrm{~Pa}\right)$.

\section{Results and discussion}

\section{Photopolymerization}

The reaction was initiated with free radical photoinitiators. The CQ absorbed visible light in the spectrum of 400-550 nm, reaching an excited state and withdrawing a hydrogen atom $(H$.$) from the tertiary amine or glycerol$ [17-20], to produce a primary radical. Figure 1 shows the reaction of initiator formation by light.

The radical triggers the homolytic cleavage in $\pi$ bonds $(\mathrm{C}=\mathrm{C})$ on dimethacrylate monomers, which produces new radicals that propagate the reaction to form the polymer $[19,20,27,29]$; this mechanism can be viewed in Fig. 2a. The literature describes that radicals in glycerol dehydrate and form alkene compounds and water (Fig. 2b) [30-32].

\section{Thermal analysis: thermogravimetry (TG), differential thermal analysis (DTA), and differential scanning calorimetry (DSC)}

The TG-DTA curves of the UDMA polymers are presented simultaneously in Fig. 3a-d. To better visualize the thermal mass loss events of each polymer, DTG was applied to TG curves and these curves are shown along with the TGDTA curves.

The TG/DTG-DTA curve for PUDMA (Fig. 3a) shows that this polymer is stable up to $213.8{ }^{\circ} \mathrm{C}$ with four mass loss steps, the first one related to solvent evaporation, and the others three related to polymer decomposition. The TG/ DTG-DTA curves for PUDMA 11 (Fig. 3b), PUDMA 13 (Fig. 3c), and PUDMA 15 (Fig. 3d) indicate that these polymers have a lower thermal stability than PUDMA (145.2, 147.0, and $147.2{ }^{\circ} \mathrm{C}$, respectively). All of them

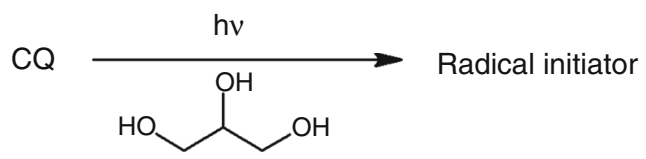

Fig. 1 Reaction for radical initiator formation exhibit a first mass loss related to solvent/water byproduct evaporation and second mass loss step associated with polymer degradation and residual glycerol evaporation; this step is related to exothermic peak at 193.1 in DTA curve. Furthermore, no residual mass was observed after the end of the analysis. In summary, the addition of glycerol provides the decrease in thermal stability when compared to PUDMA (polymer without glycerol); however, amount of glycerol did not interfere in the temperature stability considering systems with glycerol.

The TG/DTG-DTA curves for PTEGDMA, PTEGDMA 11, 13, and 15 are shown in Fig. 3e-h. The PTEGDMA is stable up to $132.6{ }^{\circ} \mathrm{C}$ with overlapping decompositions steps related to exothermic peak at 160.3 and $240.5^{\circ} \mathrm{C}$ in DTA curve. The curves for PTEGDMA 11, 13, and 15 show similar thermal stabilities (121.0, 123.2, and $125.3{ }^{\circ} \mathrm{C}$, respectively), but less than PTEGDMA. It is noted that the addition of glycerol into the TEGDMA systems decreases the thermal stability close to $10.0^{\circ} \mathrm{C}$, while in the UDMA system this variation is $66.0^{\circ} \mathrm{C}$. Another observation is that the PTEGDMA 13 and 15 exhibited five steps of mass loss, one more than the PTEGDMA and PTEGDMA 11; this extra mass loss step $\left(123.2-225.0^{\circ} \mathrm{C}\right)$ is associated with glycerol excess. It is important to emphasize that the glycerol excess did not interfere in thermal stability; however, it affected the degree of conversion and the morphology (which will be discussed forward).

Bis-GMA polymer TG-DTA curves (Fig. 3i) indicate that the sample was stable up to $227.6{ }^{\circ} \mathrm{C}$ with four steps of mass loss, the first one related to evaporation (solvent/water byproduct) and the consecutive three steps related to polymer degradation. The samples PGMA 11, and PGMA 13 (Fig. 3j, k, respectively) exhibited five steps of mass loss, one more than PGMA (associated with glycerol excess). Both samples showed a lower thermal stability (140.1 and $134.8^{\circ} \mathrm{C}$, respectively) than the PGMA. Notwithstanding, the PGMA 15 (Fig. 31) exhibited thermal stability at $142.3{ }^{\circ} \mathrm{C}$, which similar to PGMA 11 and 13 , however, showed four steps of mass loss, near to PGMA.

Finally, the TG-DTA curves for Bis-EMA polymer (Fig. $3 \mathrm{~m}$ ) noted that the sample had a thermal stability at $165.2{ }^{\circ} \mathrm{C}$ and had three mass loss steps; the first one related to solvent evaporation and the last two related to sample degradation. However, the polymers with glycerol in their structure, PEMA 11, 13, and 15 (Fig. 3n-p), had less thermal stability than PEMA (Fig. $3 \mathrm{~m}$ ) $145.2,141.9$, and $141.3{ }^{\circ} \mathrm{C}$, respectively. Moreover, these systems showed four mass loss steps, which was observed to PTEGDMA 11, 13 and 15; the little change in thermal stability (approximately $20.0{ }^{\circ} \mathrm{C}$ ) provides change in degree of conversion and morphology, which will be discussed later. Table 1 summarizes the findings from all samples. 


$$
\text { glycerol radical initiator }
$$

(a)

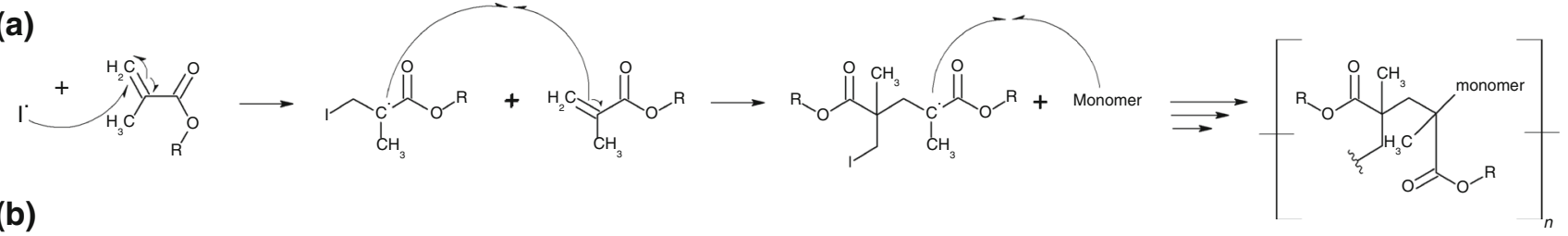

(b)

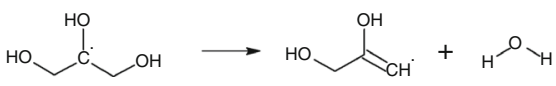

Fig. 2 Reaction mechanism: propagation and termination for polymers (a) and glycerol dehydration by radical (b)

Due to the similarity of DSC curves of each monomer using different glycerol ratios, only curves for system 13 (0.01 mol of dimethacrylate monomer for $0.03 \mathrm{~mol}$ of glycerol) are shown in Fig. 4; Table 2 shows the details of temperature peak, glass transition, and enthalpy for all polymers. The DSC curves for other systems can be viewed in the supplementary material (Figures S1, S2, and S3). The cyclic DSC curves depict the characteristic thermal events (such as evaporation, glass transition, and melting) of each polymer, which is consistent with the literature $[19,33]$. Furthermore, these data show that glycerol did not affect the thermal events.

The DSC curve for PUDMA 13 (Fig. 4a) and the other samples (Figure S1a, S2a, and S3a) did not present any thermal event at any cooling stage. However, in the first heating stage, an endothermic event in the range of $16.0-126.8{ }^{\circ} \mathrm{C}\left(\Delta H=15.3 \mathrm{~J} \mathrm{~g}^{-1}\right)$ occurred due to solvent/ water evaporation (highlighted in red) $[19,20]$. In the second heating stage, no thermal event was observed. Furthermore, the added glycerol did not provide any different thermal event (glass transition and polymerization) in UDMA systems.

The DSC curve for PTEGDMA 13 (Fig. 4b) illustrated two thermal events in the first heating stage. Thus, the first thermal event was an endothermic peak at $72.8{ }^{\circ} \mathrm{C}$ $\left(\Delta H=52.0 \mathrm{~J} \mathrm{~g}^{-1}\right)$, indicating volatilization (highlighted in red), and the second event was an exothermic peak at $126.8{ }^{\circ} \mathrm{C}\left(\Delta H=31.4 \mathrm{~J} \mathrm{~g}^{-1}\right)$, indicating thermal cure of residual monomers (highlighted in purple) $[19,34]$. In the cooling stages, no thermal events were observed. The PTEGDMA (Figure S1b) and PTEGDMA 11 (Figure S2b) exhibited similar DSC curves, in the first heating step was observed just the endothermic event associated with evaporation, and no exothermic event related to polymerization was observed. However, the sample PTEGDMA 15 (Figure S3b) presented in the first heating step an endothermic event (associated with evaporation) and an exothermic peak related to polymerization $\left(129.7^{\circ} \mathrm{C}\right)$. As observed, the glycerol excess provides the thermal polymerization, which indicates the low degree of conversion (by photopolymerization); this topic will be better discussed later.

In the DSC curves of PGMA 13 (Fig. 4c) and the other samples PGMA, PGMA 11, and PGMA 15 (Figure S1c, S2c, and S3c, respectively), an endothermic peak was observed in the first heating stage related to acetone/water byproduct evaporation (highlighted in red), with peak at $81.8{ }^{\circ} \mathrm{C}\left(\Delta H=55.7 \mathrm{~J} \mathrm{~g}^{-1}\right)$. Furthermore, in the second heating stage, a glass transition ( $T_{\mathrm{g}}$, highlighted in blue) occurred, which was calculated with the midpoint following ASTM E1356 [35]: $\quad T_{\mathrm{gPGMA}}=15.0^{\circ} \mathrm{C}$, $T_{\mathrm{gPGMA}} 11=12.4{ }^{\circ} \mathrm{C}$, and $T_{\mathrm{gPGMA}} 13=16.6{ }^{\circ} \mathrm{C}$; however, it was not possible to calculate the $T_{\mathrm{g}}$ for PGMA 15 due to its low intensity. Is not observed a correlation between glycerol amount in the polymer systems and $T_{\mathrm{g}}$ midpoint, although the intensity of glass transition decreases when the glycerol amount increases in systems, this information suggests that glycerol plays role as plasticizers in the polymer structure, due to hydrogen bonding between $-\mathrm{OH}$ groups present in glycerol and Bis-GMA structures. This effect is observed in other polymers in the literature [36-38]. In the cooling stages, no thermal events were observed for all samples.

The DSC curves for PEMA, PEMA 11, 13, and 15 (Fig. 4d, S1d, S2d, and S3d, respectively) showed two endothermic thermal events, in the first heating stage. The first event was associated to the melting of residual monomers [33], however, to PEMA 15, this event was not possible to observe, due to the overlapping by the second endothermic event (evaporation process, which was observed in all the samples). The melting enthalpies $\left(\Delta_{\text {fus }} H\right)$ in the first heating stage were: $\Delta_{\text {fus }} H_{\text {PEMA }}=2.1 \mathrm{~J} \mathrm{~g}^{-1}, \quad \Delta_{\text {fus }} H_{\text {PEMA }} 11=$ $1.5 \mathrm{~J} \mathrm{~g}^{-1}$, and $\Delta_{\text {fus }} H_{\text {PEMA } 13}=0.8 \mathrm{~J} \mathrm{~g}^{-1}$. The second heating stage exhibited just one endothermic event related to melting of residual monomers (highlighted in green) for all the samples $\left(\Delta_{\text {fus }} H_{\text {PEMA }}=2.6 \mathrm{~J} \mathrm{~g}^{-1}, \quad \Delta_{\text {fus }} H_{\text {PEMA }}{ }_{11}=\right.$ $15.7 \mathrm{~J} \mathrm{~g}^{-1}, \Delta H_{\text {PEMA }} 13=3.1 \mathrm{~J} \mathrm{~g}^{-1}$, and $\Delta_{\text {fus }} H_{\text {PEMA }} 15=$ $3.2 \mathrm{~J} \mathrm{~g}^{-1}$ ). This monomer melting is expected, due to the low 

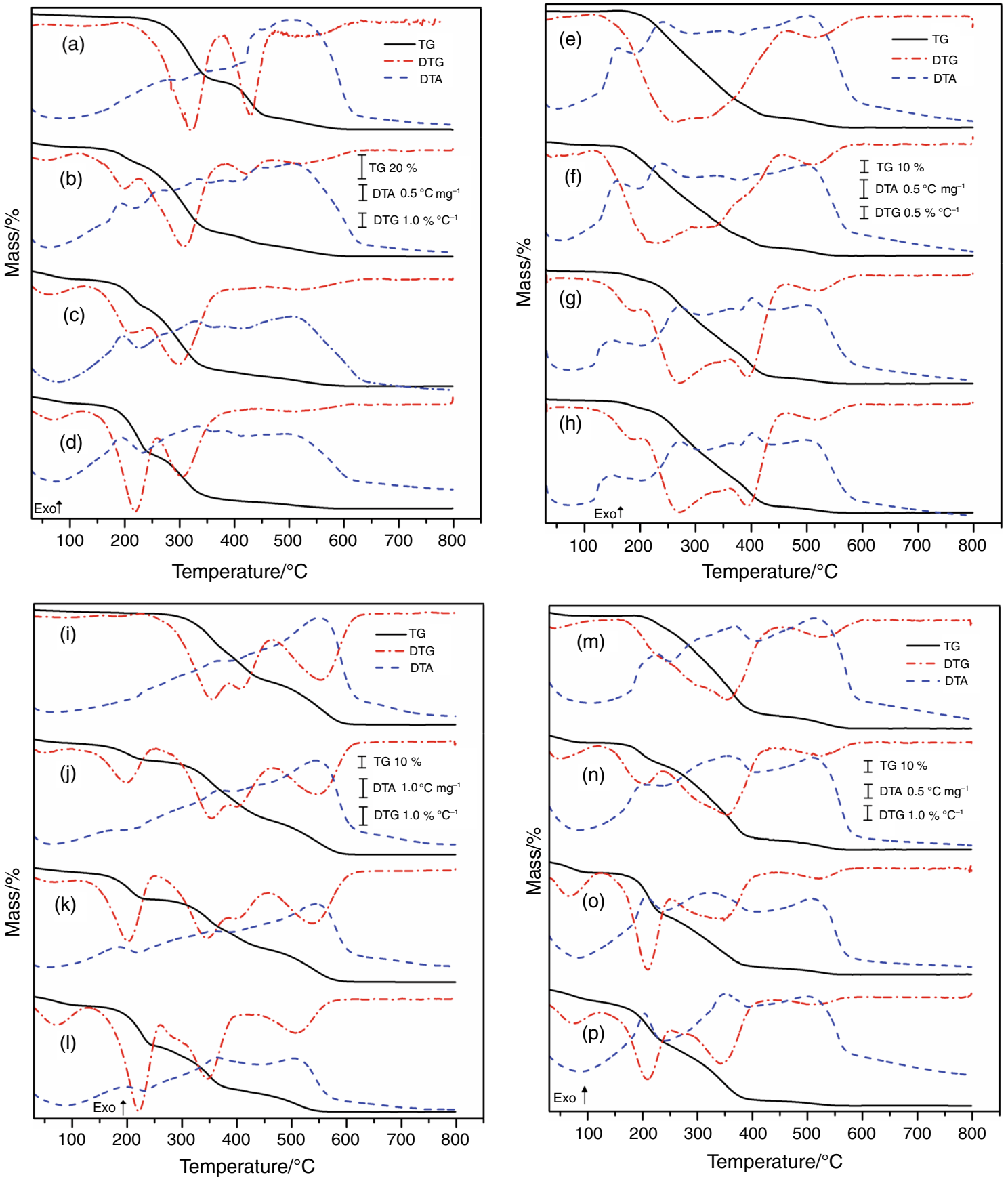

Fig. 3 TG/DTG-DTA curves for PUDMA (a), PUDMA 11 (b), PUDMA 13 (c), PUDMA 15 (d), PTEGDMA (e), PTEGDMA 11 (f), PTEGDMA 13 (g), PTEGDMA 15 (h), PGMA (i), PGMA 11 (j),

PGMA 13 (k), PGMA 15 (l), PEMA (m), PEMA 11 (n), PEMA 13 (o) and PEMA 15 (p)

conversion to polymer by photopolymerization; furthermore, no crystallization event (exothermic) was observed in the cooling stages, because this is a gradual process [33]. Moreover, the glycerol increase causes a little decrease in melting temperature, as observed in Table 2.

\section{Middle infrared spectroscopy (MIR)}

The conversion degree of dimethacrylate polymers can be viewed in Fig. 5. The reaction velocity is practically the same regardless of glycerol ratio for all samples. In the first $20 \mathrm{~s}$, the PUDMA (Fig. 5a) had the highest degree of conversion at $51.91 \%$, followed by PUDMA 13 (47.91\%), 
Table 1 Thermal events of temperature $(\theta)$, mass loss $(\Delta m)$, and temperature peak $\left(T_{\mathrm{P}}\right)$ observed in each TG-DTA curve steps of polymers

\begin{tabular}{|c|c|c|c|c|c|c|}
\hline Polymers & & 1 st step & 2nd step & 3rd step & 4th step & 5 th step \\
\hline \multirow[t]{3}{*}{ PUDMA } & $\theta^{\circ} \mathrm{C}$ & $30-213.8$ & $213.8-373.1$ & $373.1-474.1$ & $474.1-623.9$ & - \\
\hline & $\Delta m / \%$ & 3.29 & 54.99 & 31.11 & 10.17 & - \\
\hline & $T_{\mathrm{P}} /{ }^{\circ} \mathrm{C}$ & - & $270.1-340.7 * *$ & $444.1 \uparrow$ & $505.2 \uparrow$ & - \\
\hline \multirow[t]{3}{*}{ PUDMA 11} & $\theta^{\circ} \mathrm{C}$ & $30.0-145.2$ & $145.2-229.1$ & $229.1-381.7$ & $381.7-466.6$ & $466.6-643.0$ \\
\hline & $\Delta m / \%$ & 5.18 & 14.15 & 61.15 & 9.85 & 9.67 \\
\hline & $T_{\mathrm{P}} /{ }^{\circ} \mathrm{C}$ & - & $193.1 \uparrow$ & $265.0 \uparrow ; 334.6 \uparrow ; 380.0 \uparrow$ & $439.8 \uparrow$ & $505.4 \uparrow$ \\
\hline \multirow[t]{3}{*}{ PUDMA 13} & $\theta^{\circ} \mathrm{C}$ & $30.0-110.8$ & $147.0-237.6$ & $237.6-371.2$ & $371.2-611.5$ & - \\
\hline & $\Delta m / \%$ & 7.24 & 23.22 & 55.94 & 13.53 & - \\
\hline & $T_{\mathrm{P}} /{ }^{\circ} \mathrm{C}$ & - & $196.3 \uparrow$ & $331.3 \uparrow$ & $380.0 \uparrow ; 504.6 \uparrow$ & - \\
\hline \multirow[t]{3}{*}{ PUDMA 15} & $\theta^{\circ} \mathrm{C}$ & $30.0-110.0$ & $147.2-252.3$ & $252.3-371.6$ & $371.6-607.5$ & - \\
\hline & $\Delta m / \%$ & 6.34 & 42.77 & 42.58 & 8.31 & - \\
\hline & $T_{\mathrm{P}} /{ }^{\circ} \mathrm{C}$ & - & $193.6 \uparrow$ & $333.1 \uparrow ; 378.3 \uparrow$ & $433.1-619.2 *$ & - \\
\hline \multirow[t]{3}{*}{ PTEGDMA } & $\theta^{\circ} \mathrm{C}$ & $30.0-117.3$ & $132.6-294.6$ & $294.6-456.6$ & $456.6-607.9$ & - \\
\hline & $\Delta m / \%$ & 0.14 & 42.50 & 49.00 & 8.28 & - \\
\hline & $T_{\mathrm{P}} /{ }^{\circ} \mathrm{C}$ & - & $160.3 \uparrow ; 240.5 \uparrow$ & $380.7 \downarrow$ & $503.1 \uparrow$ & - \\
\hline \multirow[t]{3}{*}{ PTEGDMA 11} & $\theta^{\circ} \mathrm{C}$ & $30.0-121.0$ & $121.0-293.0$ & $293.0-453.6$ & $453.6-597.0$ & - \\
\hline & $\Delta m / \%$ & 4.29 & 38.44 & 38.99 & 6.59 & - \\
\hline & $T_{\mathrm{P}} /{ }^{\circ} \mathrm{C}$ & - & $158.1 \uparrow ; 237.8 \uparrow$ & $335.2 \uparrow ; 378.2 \downarrow$ & $495.0 \uparrow$ & - \\
\hline \multirow[t]{3}{*}{ PTEGDMA 13} & $\theta^{\circ} \mathrm{C}$ & $30.0-123.2$ & $123.2-225.0$ & $225.0-354.2$ & $354.2-457.0$ & $457.0-606.1$ \\
\hline & $\Delta m / \%$ & 3.97 & 15.46 & 49.45 & 27.14 & 3.95 \\
\hline & $T_{\mathrm{P}} /{ }^{\circ} \mathrm{C}$ & - & $149.4 \uparrow ; 209.1 \downarrow$ & $296.7 \uparrow$ & $360.2 \uparrow ; 409.4 \uparrow$ & $447.6-592.8^{*}$ \\
\hline \multirow[t]{3}{*}{ PTEGDMA 15} & $\theta^{\circ} \mathrm{C}$ & $30.0-125.3$ & $125.3-210.2$ & $210.2-341.2$ & $341.2-459.9$ & $459.9-596.7$ \\
\hline & $\Delta m / \%$ & 1.81 & 7.21 & 48.57 & 33.71 & 5.00 \\
\hline & $T_{\mathrm{P}} /{ }^{\circ} \mathrm{C}$ & - & $149.6 \uparrow ; 202.4 \downarrow$ & $270.3 \uparrow$ & $363.6 \uparrow ; 401.3 \uparrow$ & $495.0 \uparrow$ \\
\hline \multirow[t]{3}{*}{ PGMA } & $\theta^{\circ} \mathrm{C}$ & $30.0-227.6$ & $227.6-387.5$ & $387.5-464.7$ & $464.7-650.7$ & - \\
\hline & $\Delta m / \%$ & 3.10 & 35.87 & 23.26 & 36.32 & - \\
\hline & $T_{\mathrm{P}} /{ }^{\circ} \mathrm{C}$ & - & $366.9 \uparrow$ & $403.3-462.8^{*}$ & $548.8 \uparrow$ & - \\
\hline \multirow[t]{3}{*}{ PGMA 11} & $\theta^{\circ} \mathrm{C}$ & $30.0-92.8$ & $140.1-252.5$ & $252.5-383.4$ & $383.4-465.1$ & $465.1-631.3$ \\
\hline & $\Delta m / \%$ & 3.94 & 13.83 & 29.92 & 23.35 & 28.74 \\
\hline & $T_{\mathrm{P}} /{ }^{\circ} \mathrm{C}$ & - & $163.3-246.0^{* *}$ & $369.6 \uparrow$ & $411.2-464.2^{*}$ & $542.1 \uparrow$ \\
\hline \multirow[t]{3}{*}{ PGMA 13} & $\theta^{\circ} \mathrm{C}$ & $30.0-104.5$ & $134.8-249.4$ & $249.4-384.8$ & $384.8-458.5$ & $458.5-633.8$ \\
\hline & $\Delta m / \%$ & 4.13 & 22.26 & 28.12 & 16.75 & 27.79 \\
\hline & $T_{\mathrm{P}} /{ }^{\circ} \mathrm{C}$ & - & $221.4 \downarrow$ & $355.8 \uparrow$ & $400.9-466.2 *$ & $543.8 \uparrow$ \\
\hline \multirow[t]{3}{*}{ PGMA 15} & $\theta^{\circ} \mathrm{C}$ & $30.0-119.4$ & $142.3-257.7$ & 257.7-398.9 & 398.9-594.4 & - \\
\hline & $\Delta m / \%$ & 8.34 & 34.39 & 36.92 & 19.06 & - \\
\hline & $T_{\mathrm{P}} /{ }^{\circ} \mathrm{C}$ & - & $232.8 \downarrow$ & $363.4 \uparrow$ & $502.9 \uparrow$ & - \\
\hline \multirow[t]{3}{*}{ PEMA } & $\theta^{\circ} \mathrm{C}$ & $30.0-99.3$ & $165.2-442.8$ & $442.8-609.7$ & - & - \\
\hline & $\Delta m / \%$ & 3.46 & 85.73 & 10.81 & - & - \\
\hline & $T_{\mathrm{P}} /{ }^{\circ} \mathrm{C}$ & - & $227.3 \uparrow ; 367.7 \uparrow$ & $513.1 \uparrow$ & - & - \\
\hline \multirow[t]{3}{*}{ PEMA 11} & $\theta^{\circ} \mathrm{C}$ & $30.0-113.7$ & $145.2-242.4$ & $242.4-426.5$ & $426.5-604.9$ & - \\
\hline & $\Delta m / \%$ & 7.23 & 19.62 & 63.55 & 9.02 & - \\
\hline & $T_{\mathrm{P}} /{ }^{\circ} \mathrm{C}$ & - & $202.2 \uparrow$ & $355.9 \uparrow$ & $509.2 \uparrow$ & - \\
\hline \multirow[t]{3}{*}{ PEMA 13} & $\theta^{\circ} \mathrm{C}$ & $30.0-114.3$ & $141.9-249.6$ & $249.6-405.9$ & $405.9-585.0$ & - \\
\hline & $\Delta m / \%$ & 10.45 & 37.75 & 42.29 & 6.82 & - \\
\hline & $T_{\mathrm{P}} /{ }^{\circ} \mathrm{C}$ & - & $206.5 \uparrow$ & $319.7 \uparrow$ & $507.6 \uparrow$ & - \\
\hline \multirow[t]{3}{*}{ PEMA 15} & $\theta^{\circ} \mathrm{C}$ & $30.0-116.5$ & $141.3-253.9$ & $253.9-425.6$ & $425.6-582.9$ & - \\
\hline & $\Delta m / \%$ & 10.69 & 36.93 & 46.35 & 4.50 & - \\
\hline & $T_{\mathrm{P}} /{ }^{\circ} \mathrm{C}$ & - & $203.3 \uparrow$ & $354.5 \uparrow$ & $498.9 \uparrow$ & - \\
\hline
\end{tabular}

*exotherm; $\uparrow=$ exo up; $\downarrow=$ endo down; **endotherm 

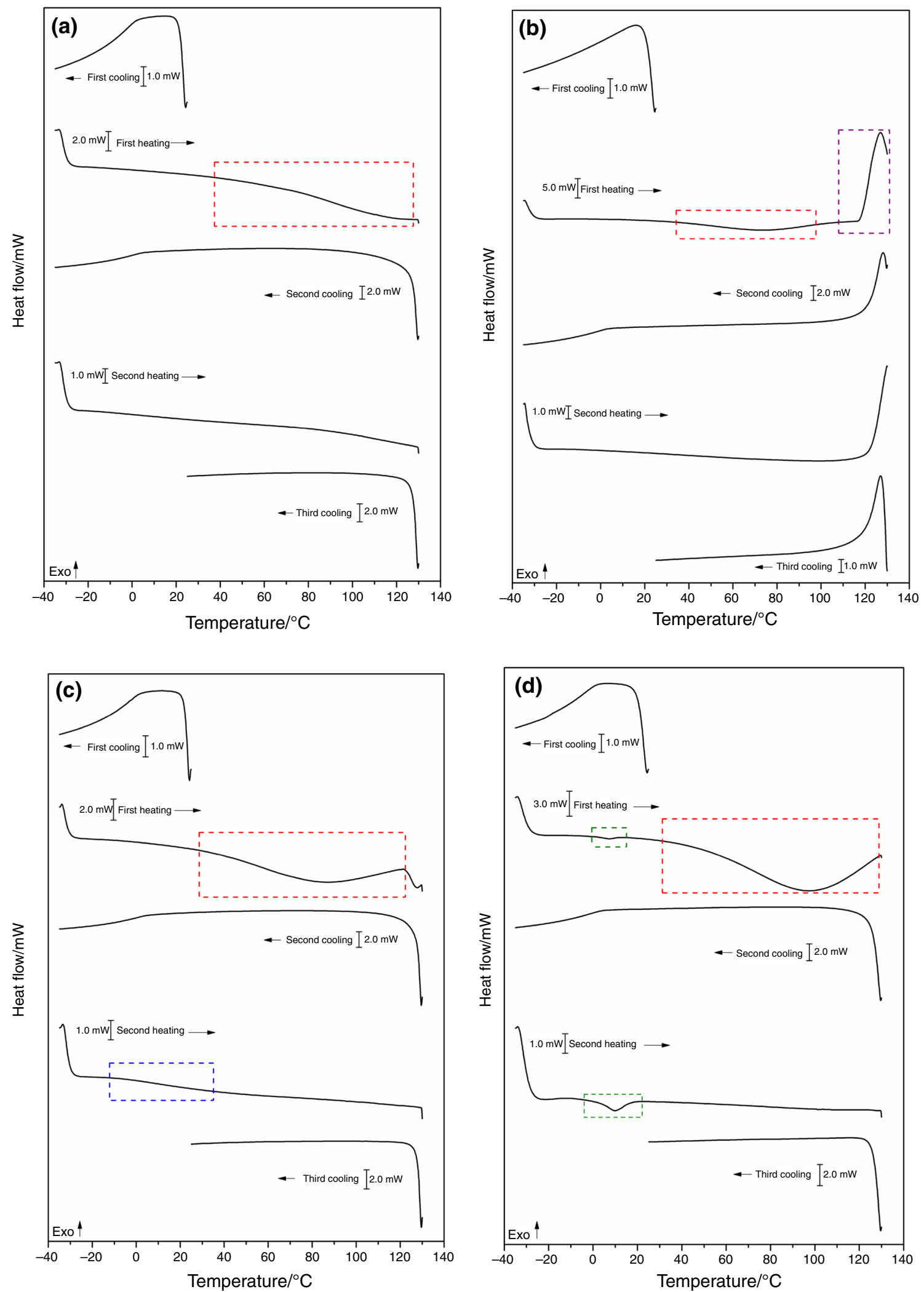

Fig. 4 DSC curves for PUDMA 13 (a), PTEGDMA 13 (b), PGMA 13 (c), PEMA 13 (d) 
Table 2 Evaporation temperature range ( $\left.T_{\text {evap }}\right)$, evaporation enthalpy $\left(\Delta H_{\text {evap }}\right)$, polymerization temperature peak $\left(T_{\text {pol }}\right)$, polymerization enthalpy $\left(\Delta H_{\mathrm{pol}}\right)$, melt temperature peak $\left(T_{\text {melt }}\right)$ of heating step, melt

\begin{tabular}{|c|c|c|c|c|c|c|c|}
\hline Polymer & $T_{\text {evap }} /{ }^{\circ} \mathrm{C}$ & $\Delta H_{\text {evap }} / \mathrm{J} \mathrm{g}^{-1}$ & $T_{\mathrm{pol}} /{ }^{\circ} \mathrm{C}$ & $\Delta H_{\mathrm{pol}} / \mathrm{J} \mathrm{g}^{-1}$ & $T_{\text {melt }} /{ }^{\circ} \mathrm{C}$ & $\Delta H_{\text {melt }} / \mathrm{J} \mathrm{g}^{-1}$ & $T_{\text {gmidppoint }}{ }^{\mathrm{a}}{ }^{\circ} \mathrm{C}$ \\
\hline PUDMA & $29.7-120.5$ & 4.5 & - & - & - & - & - \\
\hline PUDMA 11 & $40.0-119.0$ & 3.0 & - & - & - & - & - \\
\hline PUDMA 13 & $16.0-136.8$ & 15.3 & - & - & - & - & - \\
\hline PUDMA 15 & $2.1-127.6$ & 16.3 & - & - & - & - & - \\
\hline PTEGDMA & $9.8-97.3$ & 4.5 & - & - & - & - & - \\
\hline PTEGDMA 11 & $12.4-127.7$ & 112.0 & - & - & - & - & - \\
\hline PTEGDMA 13 & $7.1-113.8$ & 58.3 & 126.8 & 31.4 & - & - & - \\
\hline PTEGDMA 15 & $8.5-101.9$ & 36.2 & 129.7 & b & - & - & - \\
\hline PGMA & $35.0-130.0$ & 10.7 & - & - & - & - & 15.0 \\
\hline PGMA 11 & c & c & - & - & - & - & 12.4 \\
\hline PGMA 13 & $12.5-121.0$ & 55.7 & - & - & - & - & 16.6 \\
\hline PGMA 15 & $17.7-128.9$ & 133.4 & - & - & - & - & $\mathrm{b}$ \\
\hline PEMA & $17.1-125.8$ & 59.8 & - & - & 13.9 & 2.6 & - \\
\hline PEMA 11 & $18.4-128.3$ & 126.2 & - & - & 11.0 & 15.7 & - \\
\hline PEMA 13 & $18.4-128.9$ & 136.1 & - & - & 10.9 & 3.1 & - \\
\hline PEMA 15 & $24.3-127.6$ & 95.7 & - & - & 9.7 & 3.2 & - \\
\hline
\end{tabular}

${ }^{\mathrm{a}}$ Calculate following the ASTM E1356

${ }^{\mathrm{b}}$ Not possible to calculate

${ }^{\mathrm{c}}$ Not possible to calculate due to the events overlapping (evaporation and $T_{\mathrm{g}}$ )

PUDMA 15 (47.59\%), and PUDMA 11 (45.05\%); all the polymers at this time exhibited rigid characteristic. This behavior of conversion velocity was observed for all other times. At the end of the analysis (400 s), the total degree of conversion of PUDMA was 75.83\%, followed by PUDMA 13 (71.65\%); the PUDMA 11 and PUDMA 15 had lower degrees of conversion, about 66.88 and $67.52 \%$, respectively. Hence, the addition of glycerol in the system did not modify the reaction velocity and only slightly change the total degree of conversion, which could be due to the good miscibility of glycerol in UDMA and the formation of radical in glycerol that promotes the polymerization.

The TEGDMA system (Fig. 5b) showed no significant difference in the degree of conversion in the first $50 \mathrm{~s}$ for PTEGDMA (19.19\%), PTEGDMA 11 (20.91\%), and PTEGDMA $13(16.39 \%)$. It was not possible to calculate the degree of conversion for PTEGDMA 15, due to the immiscibility of the glycerol in the TEGDMA, forming two reagent phases. However, by $300 \mathrm{~s}$, a huge difference in the degree of conversion was observed in these three systems. Hence, the total degree of conversion was higher for PTEGDMA (79.80\%), followed by PTEGDMA 11 $(54.61 \%)$ and PTEGDMA $13(35.80 \%)$. The addition of glycerol in the TEGDMA monomer was not advantageous, because the glycerol reduces the degree of conversion and enthalpy $\left(\Delta H_{\text {melt }}\right)$ of heating step, and glass transition temperature midpoint $\left(T g_{\text {midpoint }}\right)$, observed in cycle DSC 

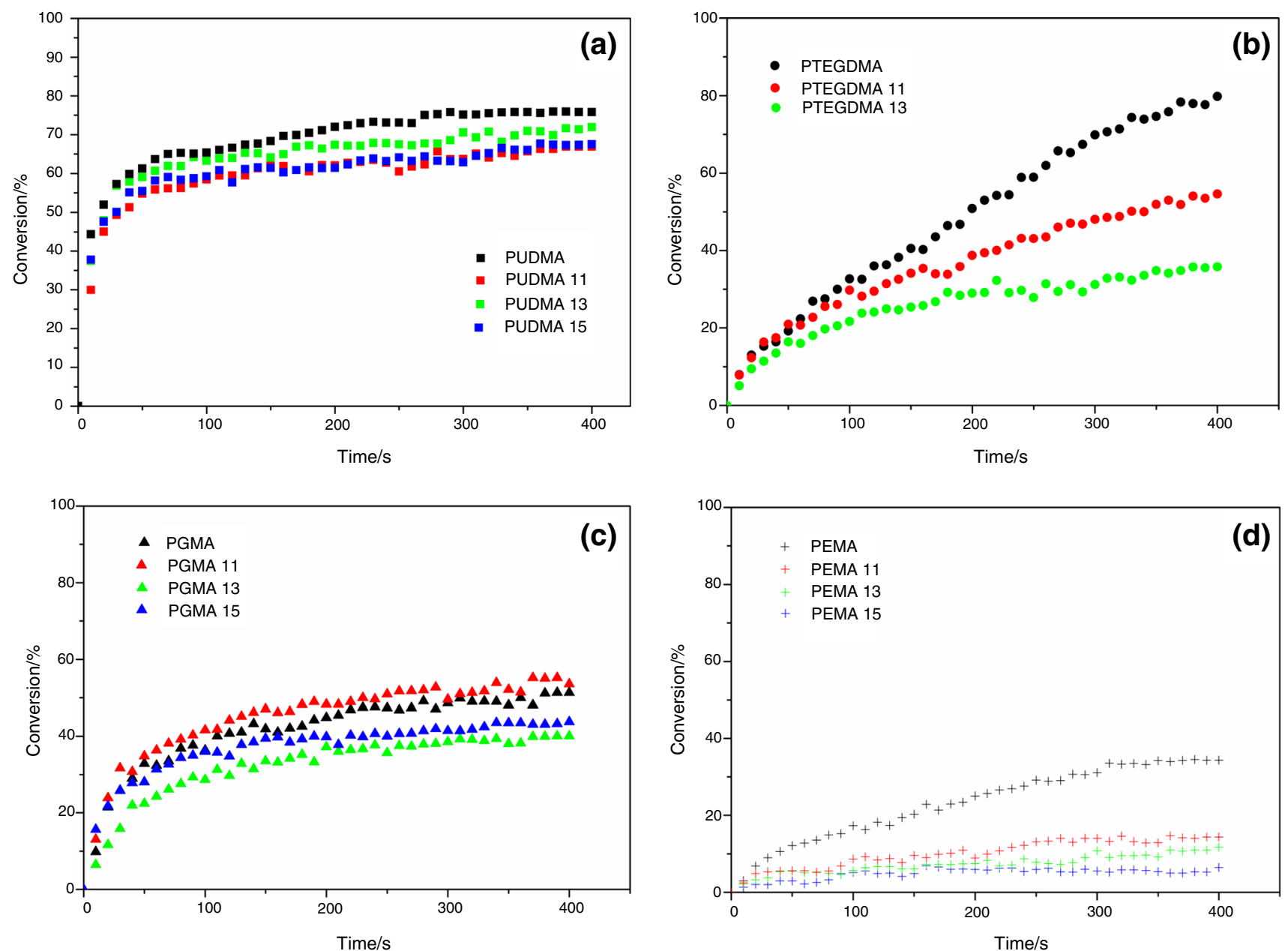

Fig. 5 Degree of conversion of all polymers with different glycerol ratios: UDMA polymers (a), TEGDMA polymers (b), Bis-GMA polymers (c), and Bis-EMA polymers (d)

Table 3 Degree of conversion (\%) of monomers to polymers with different glycerol ratios

\begin{tabular}{lrrrrrrr}
\hline Polymers & $10 \mathrm{~s} / \%$ & $20 \mathrm{~s} / \%$ & $50 \mathrm{~s} / \%$ & $100 \mathrm{~s} / \%$ & $200 \mathrm{~s} / \%$ & $300 \mathrm{~s} / \%$ & $400 \mathrm{~s} / \%$ \\
\hline PUDMA & 44.39 & 51.91 & 61.28 & 65.37 & 72.01 & 75.16 & 75.83 \\
PUDMA 11 & 29.98 & 45.05 & 54.78 & 58.41 & 62.04 & 63.72 & 66.88 \\
PUDMA 13 & 37.43 & 47.91 & 59.07 & 63.25 & 67.35 & 70.59 & 71.95 \\
PUDMA 15 & 37.82 & 47.59 & 55.49 & 59.25 & 61.39 & 62.89 & 67.52 \\
PTEGDMA & 7.94 & 12.99 & 19.19 & 32.65 & 50.89 & 69.85 & 79.80 \\
PTEGDMA 11 & 7.82 & 12.32 & 20.91 & 29.75 & 38.75 & 48.09 & 54.61 \\
PTEGDMA 13 & 5.06 & 9.48 & 16.39 & 21.65 & 28.95 & 31.19 & 35.80 \\
PGMA & 9.81 & 21.47 & 32.09 & 36.38 & 44.85 & 48.65 & 51.38 \\
PGMA 11 & 13.05 & 23.86 & 34.84 & 41.62 & 48.35 & 49.64 & 53.62 \\
PGMA 13 & 6.45 & 11.68 & 22.41 & 28.65 & 37.21 & 38.57 & 40.08 \\
PGMA 15 & 15.62 & 21.73 & 28.02 & 36.02 & 39.86 & 41.46 & 43.81 \\
PEMA & 2.99 & 6.82 & 12.16 & 17.30 & 25.01 & 31.12 & 34.37 \\
PEMA 11 & 2.48 & 4.89 & 5.63 & 8.66 & 8.89 & 13.99 & 14.37 \\
PEMA 13 & 2.19 & 3.26 & 5.51 & 5.65 & 7.47 & 10.78 & 11.72 \\
PEMA 15 & 1.33 & 2.10 & 2.96 & 5.17 & 5.96 & 5.54 & 6.48 \\
\hline
\end{tabular}



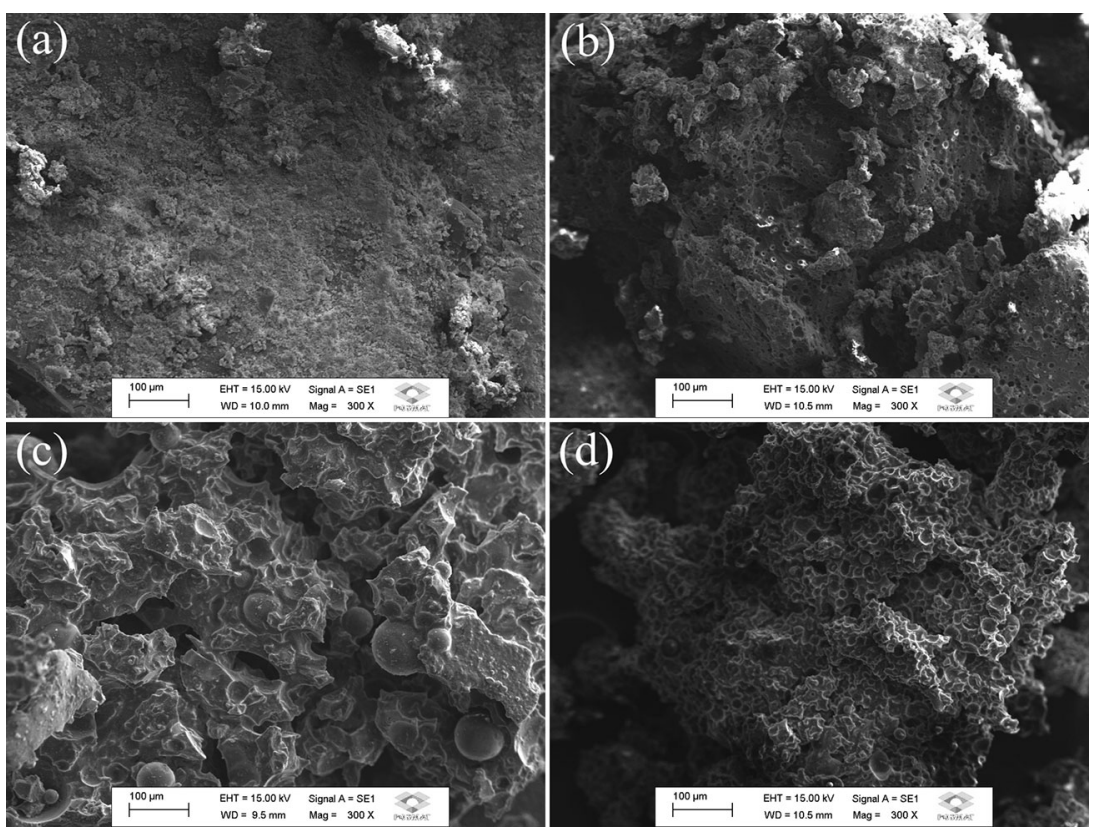

Fig. 6 SEM analysis in magnification of $\times 300$ for PUDMA (a), PUDMA 11 (b), PUDMA 13 (c), PUDMA 15 (d)
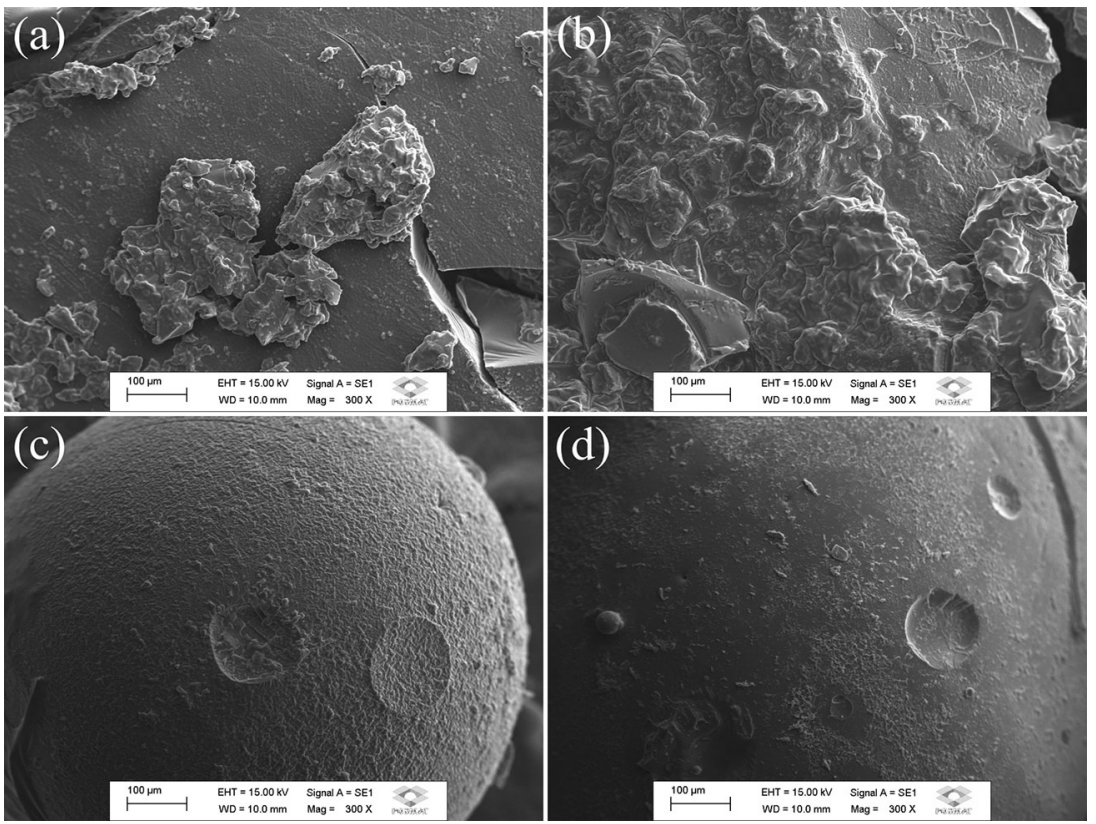

Fig. 7 SEM analysis in magnification of $\times 300$ for PTEGDMA (a), PTEGDMA 11 (b), PTEGDMA 13 (c), PTEGDMA 15 (d)

\section{Scanning electronic microscopy (SEM)}

All the SEM images are shown in Figs. 6-9. The PUDMA image (Fig. 6a) shows a sample with a cracked surface; however, the glycerol addition caused formation of some pores on the surface (Fig. 6b). The porosity is increased with the addition of glycerol, as shown in Fig. 6c, d.
Considering the conversion data, the sample PUDMA 13 had conversion close to PUDMA and is more porous than PUDMA. Furthermore, the system PUDMA 13 results in the same polymer volume that PUDMA, using $75 \%$ less of monomer; therefore, this system was considered the best sample in the UDMA system. 

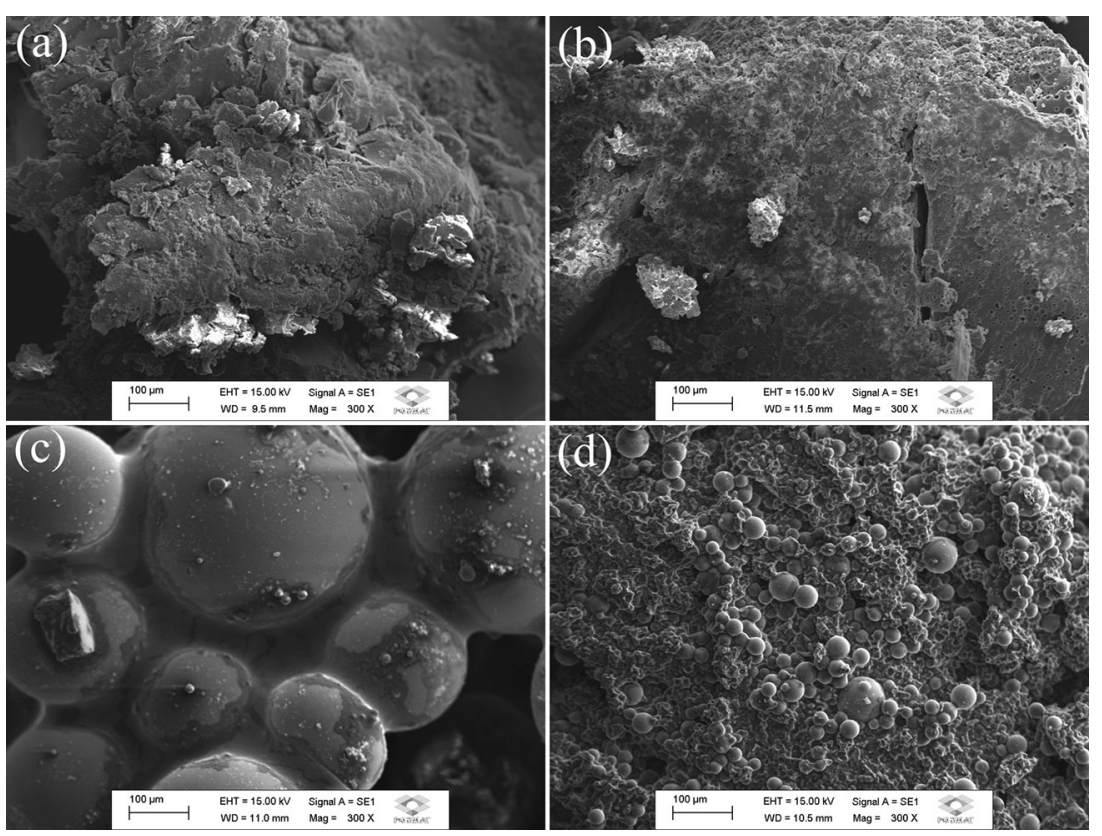

Fig. 8 SEM analysis in magnification of $\times 300$ for PGMA (a), PGMA 11 (b), PGMA 13 (c), PGMA 15 (d)
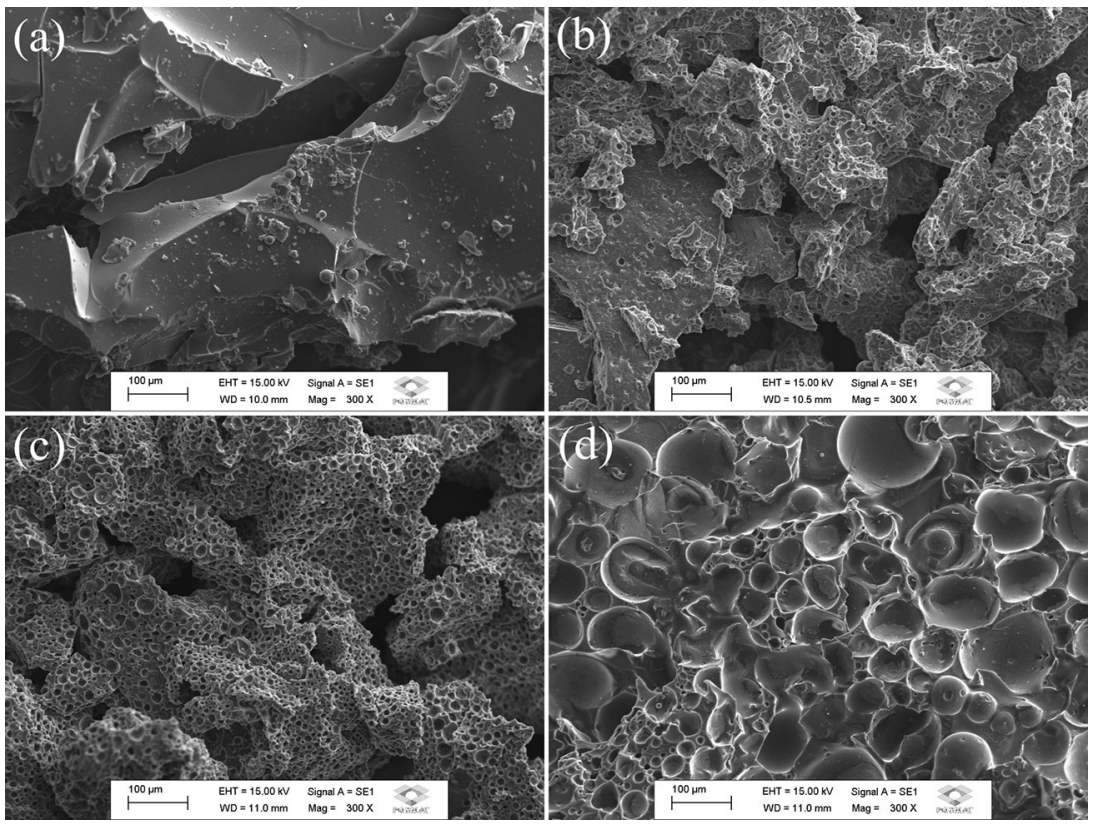

Fig. 9 SEM analysis in magnification of $\times 300$ for PEMA (a), PEMA 11 (b), PEMA 13 (c), PEMA 15 (d)

The SEM images of polymers obtained using the monomer TEGDMA are shown in Fig. 7. Note the formation of spheres with a smooth surface, without any pores. This result was expected, due to the low conversion provided by the immiscibility between glycerol and TEGDMA.
The SEM images of polymers obtained using the monomer Bis-GMA are shown in Fig. 8. The PGMA and PGMA 11 samples have the same morphology, without pores or spheres. Nevertheless, the PGMA 13 and PGMA 15 samples showed agglomerated spheres; thus, a glycerol 
quantity superior than $50 \%$ in the system modified the conversion and morphology of the polymers.

The system using Bis-EMA monomer is shown in Fig. 9. The SEM image of PEMA illustrates a polymer with fractures due to maceration. Adding glycerol in the system causes morphology change, and the large quantity of pores in PEMA 13 and PEMA 15 gives the appearance of "beehives." Therefore, the addition of glycerol in BisEMA monomer harms the total conversion and changes the polymer morphology. However, these porous polymers could be tested as filters or adsorbents.

\section{Conclusions}

The new polymers created by photopolymerization using dimethacrylate monomers and glycerol were obtained following the green chemistry principles, with no use of toxic solvents, no generation of residues, no use of thermal energy to obtain polymers, and use of renewable reagent (glycerol, biomass). These polymers with glycerol in the structure had a lower thermal stability as observed in the TG/DTG curves, which could be due to evaporation of non-reacted glycerol, water byproduct, or fragile crosslink structure. In the DSC curves of polymers from UDMA, TEGDMA, and Bis-EMA, no changes were observed in the thermal events with glycerol addition. However, the DSC curve for PGMA shows a modification of the polymer glass transition $\left(T_{\mathrm{g}}\right)$ with glycerol addition; this event changed the intensity, which suggests that glycerol worked as a plasticizer.

The addition of glycerol in the photopolymerization of UDMA was positive in the velocity and total conversion, as seen in PUDMA 13 (71.95\%), close to PUDMA $(75.83 \%)$. It was even observed for Bis-GMA, which showed a superior conversion to PGMA 11 (53.62\%) when compared to PGMA (51.38\%). In summary, the glycerol addition in the UDMA and Bis-GMA systems did not harm the polymerization and the total conversion. However, the glycerol addition in the TEGDMA and Bis-EMA system was not positive, causing lower conversion velocity and less total conversion.

The SEM images showed that the glycerol added in the UDMA system generates pores in the polymer surface, which is explained by residual glycerol. Hence, the MIR results together with the SEM images established that the best system was PUDMA 13, which used 75\% less monomer in the syntheses. For the TEGDMA system, spheres formed when glycerol was added. The PGMA and PGMA 11 had the same morphology (no pores or spheres); however, the PGMA 13 and PGMA 15 showed agglomerated spheres in their structures. Finally, the Bis-EMA system exhibited lower conversion with added glycerol as well as a greater quantity of pores.

Acknowledgements The authors wish to thank CAPES (proc. 024/2012 Pro-equipment), POSMAT/UNESP, and FAPESP (Processes: 2013/09022-7 and 2017/08820-8) for financial support.

\section{References}

1. Fouassier JP, Allonas X, Burguet D. Photopolymerization reactions under visible lights: principle, mechanisms and examples of applications. Prog Org Coat. 2003;47:16-36.

2. Jakubiak J, Nie J, Línden LA, Rabek JF. Crosslinking photocopolymerization of acrylic acid (and $\mathrm{N}$-vinylpyrrolidone) with triethylene glycol dimethacrylate initiated by camphorquinone/ ethyl-4-dimethylaminobenzoate. J Polym Sci Pol Chem. 2001;38:876-86.

3. Lu H, Lovell LG, Bowman CN. Exploiting the heterogeneity of cross-linked photopolymers to create high- $T_{\mathrm{g}}$ polymers from polymerizations performed at ambient conditions. Macromolecules. 2001;34:8021-5.

4. Ye Q, Spencer P, Wang Y, Misra A. Relationship of solvent to the photopolymerization process, properties, and structure in model dentin adhesives. J Biomater Mat Res. 2007;80:342-50.

5. Rodrigues MR, Neumann MG. Fotopolimerização: princípios e métodos. Pol Cienc Tecnol. 2003;13:276-86.

6. Lim KS, Schon BJ, Mekhileri NV, Brown GCJ, Chia CM, Prabakar S, Hooper GJ, Woodfield TBF. New visible-light photoinitiating system for improved print fidelity in gelatin-based bioinks. Biomater Sci Eng. 2016;10:1752-62.

7. Allen NS. Photoiniators for UV and visible curing of coatings: mechanisms and properties. J Photochem Photobiol Chem. 1996;100:101-7.

8. Zhao J, Lalevée J, Lu H, MacQueen R, Kable SH, Schmidt TW, Stenzel MH, Xiao P. A new role of curcumin: as a multicolor photoinitiator for polymer fabrication under household UV to red LED bulbs. Polym Chem. 2015;6:5053-62.

9. Anastas PT, Kirchhoff MM. Origins, Current Status, and Future Challenges of Green Chemistry. Accounts Chem Res. 2002;35:686-94.

10. Centi G, Perathoner S. Catalysis and sustainable (green) chemistry. Catal Today. 2003;77:287-97.

11. Hong N, Yang G, Lee J, Kim G. 3D bioprinting and its in vivo applications. J Biomed Mater Res. 2018;106:444-59.

12. Xu X, He L, Zhu B, Li J, Li J. Advances in polymeric materials for dental applications. Polym Chem. 2017;8:807-23.

13. Chang PY, Yang CH. Photopolymerization of electroactive film applied to full polymer electrochcromic device. Polym Express. 2017;11:176-86.

14. Baroli B. Photopolymerization of biomaterials: issues and potentialities in drug delivery, tissue, engineering and cell encapsulation applications. J Chemic Technol Biotechnol. 2006;81:491-9.

15. Nguyen KT, West JL. Photopolymerizable hydrogels for tissue engineering applications. Biomaterials. 2002;23:4307-14.

16. Lee J, An J, Chua CK. Fundamentals and applications of 3D printing for novel materials. Appl Mater Today. 2017;7:120-33.

17. Lalevée J, Fouassier JP. Dyes and chromophores in polymer science. 1st ed. Weinhein: Wiley; 2015.

18. Fouassier JP, Lalevée J. Photoinitiators for polymer synthesis: scope, reactivity and efficiency. 1st ed. Weinhein: Wiley; 2012.

19. Alarcon RT, Holanda BBC, Rinaldo D, Caires FJ, Almeida MV, Bannach G. Synthesis, thermal studies and conversion degree of 
dimethacrylate polymers using new non-toxic coinitiators. Quim Nova. 2017;40:363-70.

20. De Oliveira DSBL, De Oliveira LSBL, Alarcon RT, Holanda BBC, Bannach G. Use of curcumin and glycerol as an effective photoinitiating system in the polymerization of urethane dimethacrylate. J Therm Anal Calorim. 2017;128:1671-82.

21. Morrison LR. Glycerol. In: Procter and Gamble, editor. KirkOthmer encyclopedia of chemical technology. New York: Wiley; 2000. pp. 921-932.

22. Hatekayama T, Quinn FX. Thermal analysis: fundamentals and applications to polymer science. New York: Wiley; 1995.

23. Blom H, Yeh R, Wojnarowski R, Ling M. Detection of degradation of ABS Material via DSC. J Therm Anal Calorim. 2006;83:113-5.

24. Worzakowska M. Thermo-oxidative decomposition behavior of starch-g-poly(citronellyl methacrylate) and starch-gpoly(citronellyl acrylate) copolymers. J Therm Anal Calorim. 2018. https://doi.org/10.1007/s10973-017-6950-8.

25. Euvrard J, Revaux A, Bayle PA, Bardet M, Vuillaume D, Kahn A. The formation of polymer-dopant aggregates as a possible origin of limited doping efficiency at high dopant concentration. Org Electron. 2018;53:135-40.

26. Viveiros R, Lopes MI, Heggie W, Casimiro T. Green approach on the development of lock-and-key polymers for API purification. Chem Eng J. 2017;308:229-39.

27. Alarcon RT, Gaglieri C, da Silva BHST, Silva-Filho LC, Bannach G. New fluorescein dye derivatives and their use as an efficient photoinitiator using blue light LED. J Photochem Photobio Chem. 2017;343:112-8.

28. Alarcon RT, Gaglieri C, de Oliveira AR, Bannach G. Use of DSC in degree of conversion of dimethacrylate polymers: easier and faster than MIR technique. J Therm Anal Calorim. 2018. https:// doi.org/10.1007/s10973-018-6988-2.

29. Morancho JM, Cadenato A, Fernandez-Franco X, Salla JM, Ramis X. Isothermal kinetics of photopolymerization and thermal polymerization of Bis-GMA/TEGDMA resins. J Therm Anal Calorim. 2008;95:513-22.

30. Bühler W, Dinjus E, Ederer HJ, Kruse A, Mas C. Ionic reactions and pyrolysis of glycerol as competing reaction pathways in nearand supercritical water. J Supercrit Fluids. 2002;22:37-53.

31. Ott L, Bicker M, Vogel H. Catalytic dehydration of glycerol in sub- and supercritical water: a new chemical process for acrolein production. Green Chem. 2006;8:214-20.

32. Nimlos MR, Blanksby SJ, Qian X, Himmel ME, Johnson DK. Mechanism of glycerol dehydration. J Phys Chem A. 2006; 110:6145-56.

33. Bannach G, Cavalheiro CCS, Calixto L, Cavalheiro ETG. Thermoanalytical study of monomers: BisGMA, BisEMA, TEGDMA, UDMA and their mixture. Braz J Therm Anal. 2015;4:28-34.

34. Hayama T, Takahashi K, Kikutake K, Yokota I, Nemoto K. Analysis of polymerization behavior of dental dimethacrylate monomers by differential scanning calorimetry. J Oral Sci. 1999;41:9-13.

35. American Society for Testing and Materials-ASTM. ASTME1356: standard test method for assignment of the glass transition temperatures by differential calorimetry. West Conshohocken: ASTM; 2014.

36. Lavorgna M, Piscitelli F, Mangiacapra P, Buonocore GC. Study of the combined effect of both clay and glycerol plasticizer on the properties of chitosan films. Cabohydr Polym. 2010;82:291-8.

37. Quijada-Garrido I, Iglesias-González V, Mázon-Arechederra JM, Barrales-Rienda JM. The role played by the interactions of small molecules with chitosan and their transition temperatures. Glassforming liquids:1,2,3-Propantriol (glycerol). Cabohydr Polym. 2007;68:173-86.

38. Gao C, Pollet E, Avérous L. Properties of glycerol-plasticized alginate films obtained by thermo-mechanical mixing. Food Hidrocol. 2017;63:414-20. 